\title{
Clozapine-induced stuttering in the absence of known risk factors: a case report
}

\author{
Florence Jaguga* (D)
}

\begin{abstract}
Background: Stuttering is a rare side effect of clozapine. It has been shown to occur in the presence of one or more factors such as abnormal electrophysiological findings and seizures, extrapyramidal symptoms, brain pathology, and a family history of stuttering. Few case reports have documented the occurrence of clozapine-induced stuttering in the absence of these risk factors.

Case presentation: A 29-year-old African male on clozapine for treatment-resistant schizophrenia presented with stuttering at a dosage of $400 \mathrm{mg} /$ day that resolved with dose reduction. Electroencephalogram findings were normal, and there was no clinical evidence of seizures. The patient had no prior history or family history of stuttering, had a normal neurological examination, and showed no signs of extrapyramidal symptoms.
\end{abstract}

Conclusion: Clinicians ought to be aware of stuttering as a side effect of clozapine, even in the absence of known risk factors. Further research should investigate the pathophysiology of clozapine-induced stuttering.

Keywords: Clozapine, Stuttering, Risk factor, Case report

\section{Background}

Clozapine is an atypical antipsychotic with proven efficacy in the management of treatment-resistant schizophrenia [1]. It has well-documented side effects that include agranulocytosis, myocarditis, seizures, metabolic side effects, and hypersalivation [1]. Stuttering, a disorder that affects fluency of speech, is a rare side effect of clozapine that has been reported in a number of case studies [2-9]. The pathophysiologic mechanisms underlying stuttering remain unresolved but have been postulated to include dopamine dysregulation, genetic mechanisms, and structural and functional brain changes [10]. Not surprisingly, prior case reports have found clozapine-induced stuttering to co-occur with extrapyramidal symptoms $[4,5]$, seizure activity $[5,6,11,12]$, brain pathology $[4,5,13]$, and a family history of stuttering [4]. Few case reports have documented clozapine-induced stuttering in the absence of these risk factors [3].

*Correspondence: flokemboi@gmail.com

Moi Teaching \& Referral Hospital, P.O. BOX 3-30100, Eldoret, Kenya
The aim of this case report is to describe a case of clozapine-induced stuttering that occurred in the absence of seizure activity, extrapyramidal symptoms, and family history of stuttering.

\section{Case presentation}

The patient, a 29-year-old African male, was admitted in September 2019 and diagnosed with schizophrenia and comorbid cannabis and tobacco use disorders. At the time of admission, he reported a 7-year history of auditory hallucinations that were derogatory in nature, paranoid thoughts, and a lack of motivation. In addition, he reported experiencing his thoughts as though they were someone else's and had beliefs that his thoughts were being taken out of his mind. During the 7-year period, he had been on varying doses of oral olanzapine (2.5$10 \mathrm{mg} /$ day) and fluphenazine long-acting injectable (25$37.5 \mathrm{mg}$ monthly) on and off, with the two being given in combination at certain times. He reported to have been using an average of one roll of cannabis and five cigarettes per day to "feel better." original author(s) and the source, provide a link to the Creative Commons licence, and indicate if changes were made. The images or other third party material in this article are included in the article's Creative Commons licence, unless indicated otherwise in a credit line to the material. If material is not included in the article's Creative Commons licence and your intended use is not permitted by statutory regulation or exceeds the permitted use, you will need to obtain permission directly from the copyright holder. To view a copy of this licence, visit http://creativecommons.org/licenses/by/4.0/. The Creative Commons Public Domain Dedication waiver (http://creativeco mmons.org/publicdomain/zero/1.0/) applies to the data made available in this article, unless otherwise stated in a credit line to the data. 
He was initially admitted into a psychiatric ward for stabilization of acute psychotic symptoms. This was immediately followed by admission into an in-patient substance use disorder rehabilitation unit for tobacco and cannabis use disorders. Altogether, he was hospitalized for a continuous period of 5 months up to February 2020.

During this time, with supervised medication administration and no substance use, the patient failed adequate trials of oral olanzapine at $20 \mathrm{mg} /$ day and oral quetiapine at $800 \mathrm{mg} /$ day (about 9 weeks each). He reported persistent auditory hallucinations, delusions of reference, delusions of thought possession, and a lack of motivation. A brief trial of oral risperidone at $6 \mathrm{mg} /$ day was attempted for 2 weeks but was halted by a worsening of the psychotic symptoms. Consequently, a decision to initiate clozapine was made. During the last 2 weeks of hospitalization, oral clozapine was started at a dosage of $25 \mathrm{mg} /$ day. This was escalated by $25 \mathrm{mg} /$ day up to a dosage of $400 \mathrm{mg} /$ day in divided doses by the end of the second week. We utilized the United States Food and Drug Administration (FDA)-approved prescribing guidelines for clozapine administration and titration [14] in this patient. At $400 \mathrm{mg} /$ day of clozapine, the patient reported no psychotic symptoms, had improvements in motivation, and was discharged from the hospital. In addition to the antipsychotics, the patient was on nicotine gum at $8-12 \mathrm{mg} /$ day and bupropion at $150 \mathrm{mg} /$ day throughout the period of hospitalization. The bupropion and nicotine gum were, however, dropped at discharge to allow for finances to be spent on the purchase of clozapine. $\mathrm{He}$ had no cravings for tobacco and cannabis at the time of discharge.

Two weeks after discharge from hospital, while on clozapine only, the patient presented with a dysfluency characterized by random hesitations during speech and repetitions of speech sounds. This caused him to avoid social interaction. The patient had no prior history or family history of stuttering. Clinically, he had no extrapyramidal symptoms and no evidence of seizures. A neurological examination and the findings of an electroencephalogram (EEG) were both normal. The patient reported no tobacco or cannabis use after discharge from hospital, and this was corroborated by family. We did not perform a urine drug screen since the procedure was costly and not affordable to the patient.

The author was not aware of stuttering as a side effect of clozapine at the time. A literature search was done that identified a number of case reports on the subject. This prompted the clinician to consider a diagnosis of clozapine-induced stuttering. A gradual dose reduction of clozapine was attempted based on reports indicating this as an effective strategy for clozapine-induced stuttering $[2,6]$. Two weeks after onset of dose reduction, while at $200 \mathrm{mg} /$ day, the stuttering stopped but the psychotic symptoms reemerged. A second trial of a dose escalation, but more gradual this time (12.5 $\mathrm{mg}$ on alternate days), was halted 2 weeks later by reemergence of stuttering and persistence of psychotic symptoms at $300 \mathrm{mg}$ /day. This prompted the use of combination therapy with oral aripiprazole $(10 \mathrm{mg} /$ day $)$ and oral clozapine $(200 \mathrm{mg} /$ day $)$. Such a combination has been shown to be safe and effective for patients experiencing suboptimal response with clozapine [15-17]. At the time of writing this paper, the patient has been on the aripiprazole/clozapine combination for 4 weeks. The patient reports a reduction in intensity of psychotic symptoms and a complete resolution of stuttering.

\section{Discussion and conclusions}

This case supplements four case reports that have shown the occurrence of clozapine-induced stuttering in the absence of known risk factors. Murphy et al. [3] reported three cases of clozapine-induced stuttering that occurred without any evidence of seizures, movement disorders, or prior history of stuttering [3]. Similarly, Nagendrappa et al. [2] reported clozapine-induced stuttering in a 29-year-old male in the absence of a childhood developmental disorder, sensory deficits, focal neurological deficits, and seizure activity.

The exact pathophysiological mechanism(s) underpinning clozapine-induced stuttering remain unknown. Several case reports suggest an association between clozapine-induced stuttering and seizure activity. Rachamallu et al. [5] reported epileptiform discharges on the EEG recordings of a 16-year-old male with clozapineinduced stuttering. Similarly, Duggal et al. [11] reported abnormal EEG findings and generalized tonic-clonic seizures in a 28-year-old male on clozapine who developed stuttering. Both Begum [12] and Supprian et al. [7] reported myoclonic jerks in patients with clozapineinduced stuttering. In all the above cases, the stuttering and seizures resolved with administration of valproate. Our patient had normal EEG findings and no clinical evidence of seizure activity. We therefore did not offer an anticonvulsant.

Stuttering from clozapine has also been postulated to arise from extrapyramidal reactions to the medication. Interestingly, extrapyramidal symptoms have been reported to co-occur with seizures in patients with clozapine-induced stuttering Thomas et al. [18], for example, reported dyskinesia and abnormal EEG recordings in a patient who developed stuttering while on clozapine. Similarly, Rachamallu et al. [5] reported the cooccurrence of seizures and dyskinesia in a patient with clozapine-induced stuttering. In the latter case, valproate resolved the stuttering, seizures, and dyskinesia, 
suggesting seizure activity as a primary underlying mechanism for clozapine-induced stuttering [5]. In one case report, a patient on clozapine who developed stuttering and orofacial dyskinesia in the absence of seizure activity failed to respond to tetrabenazine [4]. This further casts doubt on the role of extrapyramidal mechanisms in the etiology of clozapine-induced stuttering. Our patient had no extrapyramidal symptoms throughout the period of clozapine use.

Other less well-documented risk factors for clozapineinduced stuttering include brain pathology and a family history of stuttering. A 16-year-old patient who developed stuttering while on clozapine had a history of brain contusion at the age of 14 years. [5]. Similarly, a 55-yearold male with schizophrenia who developed clozapineinduced stuttering had a history of head injury 14 years prior as well as a family history of stuttering [4]. Both patients, however, had normal brain magnetic resonance imaging (MRI) findings at the time of stuttering onset [4, 5]. A neurological examination yielded no positive findings in our patient.

Psychoactive substance use may affect clozapine metabolism. Specifically, abrupt tobacco and cannabis smoking cessation has been reported to result in increased plasma clozapine levels and to contribute to clozapine toxicity [19]. In our case, the patient denied the use of either tobacco or cannabis after discharge from hospital. Even though this was corroborated by family, urine drug levels could have been a more objective measure of use. We therefore cannot rule out tobacco and cannabis withdrawal as potential contributors to the stuttering.

Dose reduction for treating clozapine-induced stuttering has been reported to be successful at controlling the side effect without psychotic symptom decompensation $[2,6,9]$. In our case, the patient experienced psychotic symptoms at clozapine doses that did not induce stuttering and experienced stuttering at doses sufficient to produce psychotic symptom resolution. Titration of clozapine dosage to achieve a remission of both stuttering and psychotic symptoms was therefore unsuccessful, limiting the use of clozapine at therapeutic doses.

Limitations to this report are that urine drug screen levels for tobacco and cannabis were not checked at the time of stuttering since these were not affordable for the patient. In addition, we did not perform prolonged EEG monitoring and can therefore not completely rule out seizure activity.

This case emphasizes the need for clinicians to be aware of clozapine-induced stuttering, even in the absence of known risk factors. Further, it highlights the need for future research to investigate the pathophysiology of clozapine-induced stuttering.

\section{Abbreviations}

EEG: Electroencephalogram; FDA: Food and Drug Administration; mg: Milligrams; MRI: Magnetic resonance imaging.

\section{Acknowledgements}

Not applicable

\section{Authors' contributions}

FJ drafted the manuscript for submission. FJ was also the primary doctor for the patient presented in the case report. The author read and approved the final manuscript.

\section{Funding}

There are no sources of funding to declare

Availability of data and materials

Not applicable

\section{Declarations}

Ethics approval and consent to participate

Not applicable

\section{Consent for publication}

Written informed consent was obtained from the patient for publication of this case report and any accompanying images. A copy of the written consent is available for review by the Editor-in-Chief of this journal.

\section{Competing interests}

The author declares that she has no competing interests.

Received: 17 June 2020 Accepted: 18 March 2021

Published online: 17 April 2021

\section{References:}

1. Haidary HA, Padhy RK. Clozapine. [Updated 2020 Mar 24]. In: StatPearls [Internet]. Treasure Island (FL): StatPearls Publishing; 2020. https://www. ncbi.nlm.nih.gov/books/NBK535399/. Accessed 22 Feb 2021.

2. Nagendrappa S, Sreeraj VS, Venkatasubramanian G. "I stopped hearing voices, started to stutter" - a case of clozapine-induced stuttering. Indian J Psychol Med. 2019;41(1):97-8.

3. Murphy R, Gallagher A, Sharma K, Ali T, Lewis E, Murray I, et al. Clozapineinduced stuttering: an estimate of prevalence in the west of Ireland. Ther Adv Psychopharmacol. 2015;5(4):232-6.

4. Lyall M, Pryor A, Murray K. Clozapine and speech dysfluency: two case reports. Psychiatr Bull. 2007;31(1):16-8.

5. Rachamallu V, Haq A, Song MM, Aligeti M. Clozapine-induced microseizures, orofacial dyskinesia, and speech dysfluency in an adolescent with treatment resistant early onset schizophrenia on concurrent lithium therapy. Case Rep Psychiatry. 2017. https://doi.org/10.1155/2017/73590 95.

6. Grover S, Verma AK, Nebhinani N. Clozapine-induced stuttering: a case report and analysis of similar case reports in the literature. Gen Hosp Psychiatry. 2012;34(6):703.e1-703.e7033. https://doi.org/10.1016/j.genho sppsych.2012.02.010.

7. Supprian T, RetzW, Deckert J. Clozapine-induced stuttering: epileptic brain activity? Am J Psychiatry. 1999;156(10):1663-4. https://doi.org/10. 1176/ajp.156.10.1663.

8. Hallahan BP, Murray IT, Doyle PG. Clozapine induced stuttering. Ir J Psychol Med. 2007;24(3):121.

9. Krishnakanth M, Haridas Phutane V, Muralidharan K. Clozapine-induced stuttering: a case series. Prim Care Companion J Clin Psychiatry. 2008;10(4):333-4. https://doi.org/10.4088/pcc.v10n0411e.

10. Perez HR, Stoeckle JH. Stuttering: clinical and research update. Can Fam Physician. 2016;62(6):479-84.

11. Duggal HS, Jagadheesan K, Nizamie SH. Clozapine-induced stuttering and seizures. Am J Psychiatry. 2002;159(2):315. https://doi.org/10.1176/ appi.ajp.159.2.315. 
12. Begum M. Clozapine-induced stuttering, facial tics and myoclonic seizures: a case report. Aust N Z J Psychiatry. 2005;39(3):202.

13. Bär KJ, Häger F, Sauer H. Olanzapine- and clozapine-induced stuttering: a case series. Pharmacopsychiatry. 2004;37(3):131-4.

14. U.S. Food and Drug Administration. CLOZARIL ${ }^{\circledR}$ (clozapine) tablets Label. 2014. Available from: https://www.accessdata.fda.gov/drugsatfda_docs/ label/2017/019758s084lbl.pdf. Accessed 22 Feb 2021

15. Benedetti A, Di Paolo A, Lastella M, Casamassima F, Candiracci C, Litta A, et al. Augmentation of clozapine with aripiprazole in severe psychotic bipolar and schizoaffective disorders: a pilot study. Clin Pract Epidemiol Ment Heal. 2010;6(1):30-5

16. Muscatello MRA, Bruno A, Pandolfo G, Micò U, Scimeca G, Di Nardo F, et al. Effect of aripiprazole augmentation of clozapine in schizophrenia: a double-blind, placebo-controlled study. Schizophr Res. 2011;127(1-3):93-9.

17. Ashton AK. Aripiprazole augmentation of clozapine refractory schizophrenia. Psychiatry (Edgmont). 2005;2(2):18.
18. Thomas P, Lalaux N, Vaiva G, Goudemand M. Dose-dependent stuttering and dystonia in a patient taking clozapine. Am J Psychiatry. 1994;151(7):1096. https://doi.org/10.1176/ajp.151.7.1096a.

19. Zullino DF, Delessert D, Eap CB, Preisig M, Baumann P. Tobacco and cannabis smoking cessation can lead to intoxication with clozapine or olanzapine. Int Clin Psychopharmacol. 2002;17(3):141-3.

\section{Publisher's Note}

Springer Nature remains neutral with regard to jurisdictional claims in published maps and institutional affiliations.
Ready to submit your research? Choose BMC and benefit from:

- fast, convenient online submission

- thorough peer review by experienced researchers in your field

- rapid publication on acceptance

- support for research data, including large and complex data types

- gold Open Access which fosters wider collaboration and increased citations

- maximum visibility for your research: over 100M website views per year

At BMC, research is always in progress.

Learn more biomedcentral.com/submissions 